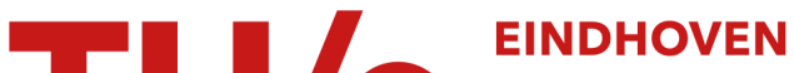 \\ UNIVERSITY OF \\ TECHNOLOGY
}

\section{The influence of shrinkage on drying behaviour of clays}

Citation for published version (APA):

Ketelaars, A. A. J., Kaasschieter, E. F., Coumans, W. J., \& Kerkhof, P. J. A. M. (1994). The influence of shrinkage on drying behaviour of clays. Drying Technology, 12(7), 1561-1574.

https://doi.org/10.1080/07373939408962187

DOI:

10.1080/07373939408962187

Document status and date:

Published: 01/01/1994

\section{Document Version:}

Publisher's PDF, also known as Version of Record (includes final page, issue and volume numbers)

\section{Please check the document version of this publication:}

- A submitted manuscript is the version of the article upon submission and before peer-review. There can be important differences between the submitted version and the official published version of record. People interested in the research are advised to contact the author for the final version of the publication, or visit the $\mathrm{DOI}$ to the publisher's website.

- The final author version and the galley proof are versions of the publication after peer review.

- The final published version features the final layout of the paper including the volume, issue and page numbers.

Link to publication

\section{General rights}

Copyright and moral rights for the publications made accessible in the public portal are retained by the authors and/or other copyright owners and it is a condition of accessing publications that users recognise and abide by the legal requirements associated with these rights.

- Users may download and print one copy of any publication from the public portal for the purpose of private study or research.

- You may not further distribute the material or use it for any profit-making activity or commercial gain

- You may freely distribute the URL identifying the publication in the public portal.

If the publication is distributed under the terms of Article 25fa of the Dutch Copyright Act, indicated by the "Taverne" license above, please follow below link for the End User Agreement:

www.tue.nl/taverne

Take down policy

If you believe that this document breaches copyright please contact us at:

openaccess@tue.nl

providing details and we will investigate your claim. 


\title{
THE INFLUENCE OF SHRINKAGE ON DRYING BEHAVIOUR OF CLAYS
}

\author{
A.A.J. Ketelaars ${ }^{1}$, E.F. Kaasschieter ${ }^{2}$, W.J. Coumans ${ }^{1}{ }^{*}$, P.J.A.M. Kerkhof ${ }^{1}$ \\ ${ }^{1}$ Department of Chemical Engineering and ${ }^{2}$ Department of Mathematics and \\ Computing Science, Eindhoven University of Technology, P.O.Box 513, \\ $5600 \mathrm{MB}$ Eindhoven, the Netherlands
}

Key Words and Phrases: diffusion coefficient; drying curves; isotropic shrinkage; simulations; unidirectional shrinkage

\section{ABSTRACT}

A correct description of the evolution of moisture concentration profiles in shrinking materials is complicated by the influence of shrinkage on mass transfer. Shrinkage has to be accounted for in the diffusion equation. Simulations have been performed for three types of shrinkage: isotropic, unidirectional and no shrinkage. Since many materials show isotropic shrinkage behaviour, unidirectional and no shrinkage should be considered as approximations of the actual material behaviour. Various numerical simulations show that for clays the influence of the type of shrinkage on drying curves is small.

\section{INTRODUCTION}

Drying is an important unit operation which is used in many production processes [e.g. Genskow, 1989; Mujumdar, 1991]. In e.g. the clay brick- and tile manufacturing industry drying plays an essential role in the production process.

\footnotetext{
to whom correspondence should be sent
} 
The annual turnover of the Dutch ceramic industry is approximately 1.7 milliard standard sized clay bricks ( $\mathrm{Hfl} .500$ million), 45 million roof tiles (Hfl. 70 million) and 15 million $\mathrm{m}^{2}$ tiles (Hfl. 250 million) [Jacobs, 1989]. In the production of clay bricks alone, 1 million tons of water is removed annually by means of drying.

The removal of water from clays is accompanied by shrinkage. In Figure 1 shrinkage curves typical for clays are given [Ketelaars, 1992]. In industrial practice the initial moisture content of the clay is high in order to obtain a workable clay, which can be mixed and moulded into the desired shape. Before sintering this so-called 'green' clay at high temperature, almost all water has to be removed in a drying step. Shrinkage occurs during the initial part of this drying process.

Typical for clays is that maximum shrinkage occurs at moisture contents above the shrinkage limit, whereas no shrinkage occurs at moisture contents below this limit. An identical mathematical formulation of the diffusion equation can be used for these two types of shrinkage. A problem, however, with respect to the numerical solution of the diffusion equation in the shrinkage region, is the change in size and shape of the material. Usually a grid for the numerical solution is attached to the initial dimensions of the body. During the drying process the body will move through this grid, making the numerical solution complicated. This moving boundary problem can be handled by a transformation of the spatial coordinates.

In principle deformations due to shrinkage and stresses have to be taken into account for the transformation of the spatial coordinate. Calculation of deformations due to stresses implies that the balance of momentum has to be solved in addition to the diffusion equation, which leads to a set of coupled partialdifferential equations. However, by assuming some type of shrinkage it is possible to transform the spatial coordinate without taking into account the balance of momentum. This approach has been used for e.g. unidirectional shrinkage [e.g. Coumans, 1987; Kechaou et al., 1989] or isotropic shrinkage [e.g. Roques, 1991; Jomaa et al., 1991]. 


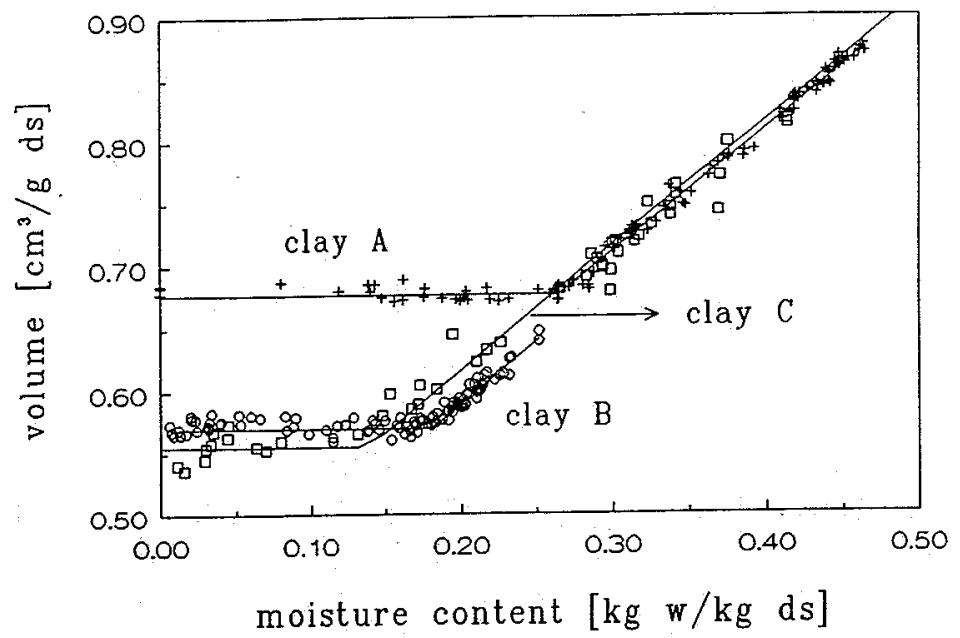

FIGURE 1. Shrinkage curve typical for clays. Clay $A$ is a kaolinite clay used as raw material in the fine ceramics industry. Clay $B$ and $C$ are representatives of the raw materials used in the Dutch structural ceramics industry.

The shrinkage model assumed in the transformation of the spatial coordinate, influences the simulated drying behaviour. Consequently, the diffusion coefficient, which is derived from experimental drying curves, depends on the way in which shrinkage is accounted for in the diffusion model. Therefore the influence of shrinkage on drying behaviour is studied by means of simulations for various types of shrinkage and drying geometries.

\section{DIFFUSION MODEL}

It has been shown [e.g. Lartigue et al., 1989; Ketelaars, 1992] that a diffusion model can be derived from a fundamental mechanistic model after some simplifications. The apparent diffusion coefficient $D$ should be considered a lump parameter and in general will be a function of moisture content. Here we will postulate that a diffusion model may be used to describe mass transfer in this specific case. 


\subsection{Diffusion Equation}

The flux of moisture is defined with respect to the solid phase velocity as

$$
\rho_{\mathrm{m}} \underline{v}_{\mathrm{m}}=\rho_{\mathrm{m}} \underline{v}_{\mathrm{s}}-\rho_{\mathrm{s}} \mathrm{D}(\mathrm{u}) \underline{\nabla u},
$$

Note that this equation is in fact the definition of the diffusion coefficient. Combination of this equation with the mass balance for moisture and solid

$$
\begin{array}{r}
\frac{\partial \rho_{\mathrm{m}}}{\partial \mathrm{t}}=-\underline{\nabla} \cdot\left(\rho_{\mathrm{m}} \underline{v}_{\mathrm{m}}\right), \\
\frac{\partial \rho_{s}}{\partial \mathrm{t}}=-\underline{\nabla} \cdot\left(\rho_{s} \underline{v}_{s}\right),
\end{array}
$$

leads to the form of the diffusion equation which is used in this study:

$$
\frac{\partial u}{\partial t}+\underline{v}_{s} \cdot \underline{\nabla} u=\frac{1}{\rho_{s}} \underline{\nabla} \cdot\left(\rho_{s} D(u) \underline{\nabla} u\right)
$$

As the initial condition a uniform moisture content distribution is assumed:

$$
u(\underline{x}, 0)=u_{0} \text {. }
$$

For the boundary conditions two cases are considered. First there is no flux through insulated boundaries and planes of symmetry, i.e.

$$
\underline{n} \cdot\left(\rho_{s} D(u) \underline{\nabla} u\right)=0 \text {. }
$$

Secondly, convective mass transfer is assumed to take place at faces submitted to drying such that mass transfer resistance in the gas phase is concentrated in a small boundary layer, i.e.

$$
-\underline{n} \cdot\left(\rho_{s} D(u) \underline{\nabla} u\right)=k\left(C^{i}(u)-C^{\infty}\right) \text {. }
$$

The mass transfer coefficient $k$ depends on many factors such as velocity of the 
drying air, structure of the surface, orientation of the surface with regard to the direction of the air, etc. A lot of empirical correlations are available for the determination of $k$ as a function of these variables. In general, however, $k$ has to be determined experimentally for the specific experimental set-up under consideration. $C^{i}$ is the vapour concentration of the air at the solid/air interface, which is in equilibrium with the moisture content in the material at the interface. The equilibrium relation $\mathrm{C}=\mathrm{f}(\mathrm{u})$ is given by the sorption isotherm.

\subsection{Transformation of the Spatial Coordinate}

Essential in the transformation of the spatial coordinates $\underline{x}$ is the introduction of solid coordinates z. Every mass element of solid has solid coordinates $\underline{z}$ and spatial coordinates $\underline{x}(t)$. The solid coordinates are independent of time and are defined according to

$$
\underline{z}=\underline{x}(0) \text {. }
$$

The transformation of the diffusion equation from $\underline{x}(t)$ to $\underline{z}$ is presented in detail elsewhere [Ketelaars, 1992]. In this transformation the so called shrinkage factor $\Psi_{s}(u)$ is used, i.e.

$$
\Psi_{s}(u)=\frac{\rho_{s}}{\rho_{s, 0}} .
$$

In this article the results of the transformation will be given for three types of shrinkage.

\section{- Local Isotropic Shrinkage}

Local-isotropic shrinkage means that on a small, local level a material tends to shrink isotropically. This holds for many materials such as clays, inorganic gels or (liquid) foods. For local isotropic shrinkage the diffusion equation with respect to the solid coordinates $\underline{z}$ reads

$$
\frac{\partial u}{\partial t}=\underline{\nabla} \cdot\left(D(u) \Psi_{s}(u)^{2 / 3} \underline{\nabla} u\right) .
$$


The corresponding boundary conditions are

$$
\begin{aligned}
& -\underline{n} \cdot\left(\rho_{s, 0} \Psi_{s}(u)^{4 / 3} D(u) \underline{\nabla u}\right)=k\left(C^{i}(u)-C^{\infty}\right) \\
& -\underline{n} \cdot\left(\rho_{s, 0} \Psi_{s}(u)^{4 / 3} D(u) \underline{\nabla u}\right)=0 .
\end{aligned}
$$

\section{- Unidirectional Shrinkage}

Unidirectional shrinkage means that the reduction of volume due to water losses is totally accounted for by shrinkage in one direction. E.g. in drying a slab from the upper surface, it is assumed that only the thickness of the slab reduces and not the surface area. In practice unidirectional shrinkage occurs only under special conditions such as drying of some polymers and drying of a thin constrained film [Scherer, 1987]. In literature, however, the unidirectional shrinkage model is encountered quite often [Evans et al., 1975; Coumans, 1987; Kechaou et al., 1989], mainly because the transformation of the spatial coordinate is simple [e.g. Crank, 1956; Philip, 1969]. The assumption of unidirectional shrinkage is most often related to a one-dimensional drying problem where moisture is transferred in one direction only. Therefore in many cases only one coordinate has to be considered $\left(x_{1}\right.$ or $\left.z_{1}\right)$. The diffusion equation and the boundary conditions with respect to this solid coordinate $z_{1}$ become

$$
\begin{aligned}
& \frac{\partial u}{\partial t}=\frac{\partial}{\partial z_{1}}\left[\Psi_{s}(u)^{2} D(u) \frac{\partial u}{\partial z_{1}}\right] \\
& -\rho_{s, 0} \Psi_{s}(u)^{2} D(u) \frac{\partial u}{\partial z_{1}}=k\left(C^{i}(u)-C^{\infty}\right) \\
& -\rho_{s, 0} \Psi_{s}(u)^{2} D(u) \frac{\partial u}{\partial z_{1}}=0
\end{aligned}
$$

- No Shrinkage

For some-materials, the amount of shrinkage is small and the effect of shrinkage on drying might be negligible [Lartigue et al., 1989]. For clays the neglect of shrinkage can be considered as an approximation of the actual shrinkage behaviour. If shrinkage is neglected, the spatial coordinates $\underline{x}$ are identical to the solid coordinates $\underline{z}$ during the whole drying process:

$$
\frac{\partial u}{\partial \mathrm{t}}=\underline{\nabla} \cdot(D(u) \underline{\nabla} u),
$$




$$
\begin{aligned}
& -\underline{n} \cdot\left(\rho_{s, 0} D(u) \underline{\nabla} u\right)=k\left(C^{i}(u)-C^{\infty}\right) \\
& -\underline{n} \cdot\left(\rho_{s, 0} D(u) \underline{\nabla} u\right)=0
\end{aligned}
$$

\section{- Comparison of Various Shrinkage Models}

In the preceding sections various shrinkage models have been considered. The shrinkage model assumed in the transformation of the spatial coordinates, influences the diffusion equation and the boundary condition in the solid coordinates system. Therefore, drying behaviour will depend on the type of shrinkage in a complicated way. Numerical simulations, solving the diffusion equation for various shrinkage models, will be necessary to gain insight on the influence on drying behaviour.

\section{THE INFLUENCE OF SHRINKAGE ON DRYING BEHAVIOUR}

\subsection{One-dimensional Simulations}

Simulations are performed on one-dimensional drying of a slab with a thickness of $3 \mathrm{~mm}$. Drying curves are calculated assuming local isotropic shrinkage, unidirectional shrinkage and no shrinkage in the transformation of the spatial coordinates. In Figure 2 typical results are given for clay $A$, for the material properties used in this simulation see the appendix. The numerical solution is obtained using a standard finite element package SEPRAN [Segal,1984], which has been adapted for the problem studied here [Kaasschieter, 1992].

In the isotropic shrinkage model the external surface area of the slab decreases, whereas in the unidirectional shrinkage and no-shrinkage model the surface area of the slab remains constant. As a consequence, drying will proceed more slowly for the isotropic shrinkage model than for the unidirectional or the noshrinkage model. For this clay, the surface area decrease is approximately $12 \%$ for isotropic shrinkage. It appears from computer simulations that the effect of surface area decrease on the drying curve is limited. 


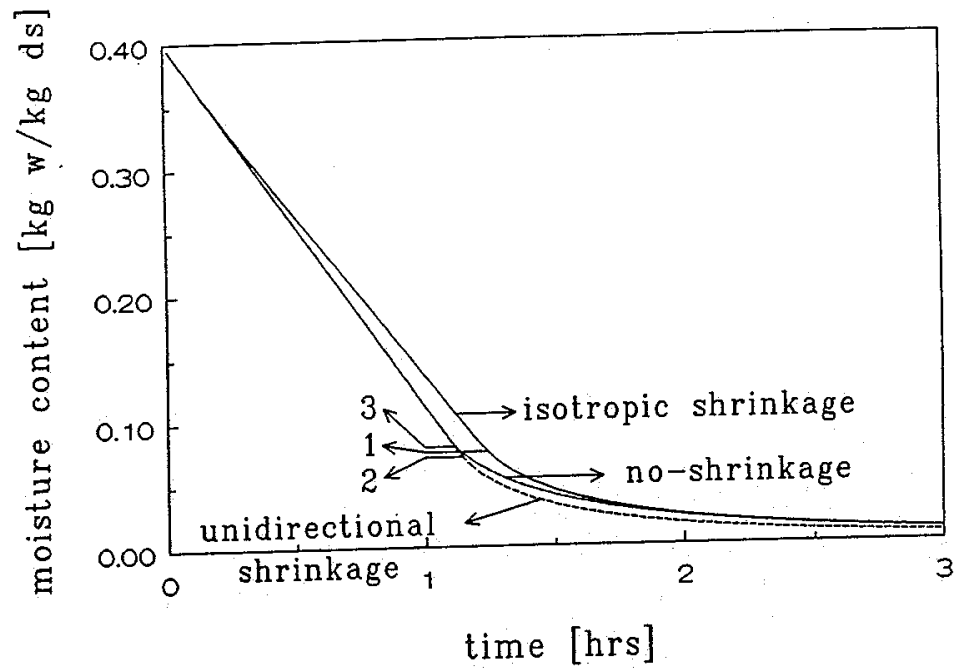

FIGURE 2. Computed drying curves for clay A using different shrinkage models. Numbers indicate the average moisture content for which the period of falling drying flux starts: 1 , local isotropic shrinkage; 2 , unidirectional shrinkage; 3 , noshrinkage.

The thickness of the slab decreases due to shrinkage. In the isotropic shrinkage model the final thickness for a slab with an initial thickness of $3 \mathrm{~mm}$ is approximately $2.8 \mathrm{~mm}$, in the unidirectional shrinkage model it is $2.5 \mathrm{~mm}$. Obviously, since all shrinkage is assumed to occur in one direction, the reduction of the slab-thickness is the highest in the unidirectional shrinkage model. The diffusion path-length for moisture in the slab is therefore, at a given average moisture content, the smallest for unidirectional shrinkage and also the moisture concentration profiles will be the flattest. Consequently, the period of falling drying flux will be entered with the lowest average moisture content for the unidirectional shrinkage model (number 2 in Figure 2). On the other hand the period of falling drying flux will be entered with the highest average moisture content for the no shrinkage model (number 3 in Figure 2). Again, there are only minor differences between the various drying curves.

During drying the thickness of the slab is higher for the no-shrinkage model than for the isotropic shrinkage model. This causes a lower drying flux for the no 
shrinkage model towards the end of the drying process. On the other hand, the surface area decrease causes a smaller drying rate for the isotropic shrinkage model compared to the no-shrinkage model. Apparently (see Figure 2), these two effects compensate, causing the good agreement of the drying curves for the two models. These two effects do not compensate however for the unidirectional and isotropic shrinkage model. The smaller slab-thickness and the larger surface area both cause a higher drying rate for the unidirectional shrinkage model compared to the isotropic shrinkage model.

\subsection{Simulations of Multi-dimensional Drying}

The simulations in the preceding section have been performed for a one-dimensional situation (thin slab). It was concluded that for clays the overall effect of shrinkage is small. In practice, however, drying of clays occurs in more dimensions and for larger geometries such as bricks. Therefore the simulations are extended to larger multi-dimensional geometries. The simulations are performed for a cube of $5 \times 5 \times 5 \mathrm{~cm}$, which is one-eighth of a larger cube (see Figure 3 ). Drying occurs at the shaded faces, no moisture is transferred through the other faces (planes of symmetry or no-flux boundaries). Depending on the numbers of faces where drying occurs, the problem is one-dimensional (1D), two-dimensional (2D) or three-dimensional (3D). Since the physical relevance of the unidirectional shrinkage model is, for clays, restricted to one dimensional geometries, only the isotropic and no-shrinkage models are considered. In order to be able to compare the drying curves for the various geometries, the initial drying flux $(\mathrm{kg}$ $\mathrm{m}^{-2} \mathrm{~s}^{-1}$ ) has been adapted in such a way that the initial drying rate $\left(\mathrm{kg} \mathrm{s}^{-1}\right)$ is constant, e.g. in the three-dimensional situation the initial flux is one-third of the initial flux in the one-dimensional situation.

The results, although on a larger time-scale, are very similar to the results for one-dimensional drying of a thin slab. First of all there is the deviation of the drying curve for the isotropic shrinkage model due to a decrease in surface area. Secondly, the drying curves merge after some time as a result of the larger dimensions of the cube in the no-shrinkage model. The results for the one-, twoand three dimensional simulations are in qualitative agreement. 

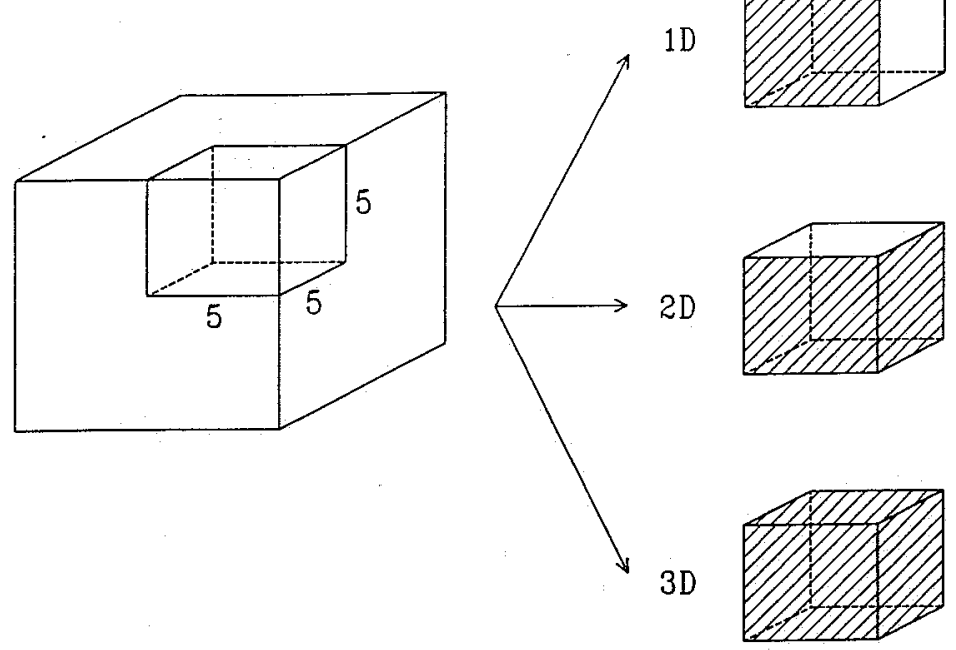

FIGURE 3. Multi-dimensional geometries used in simulations. Drying occurs at shaded faces, other faces are isolated boundaries or planes of symmetry.

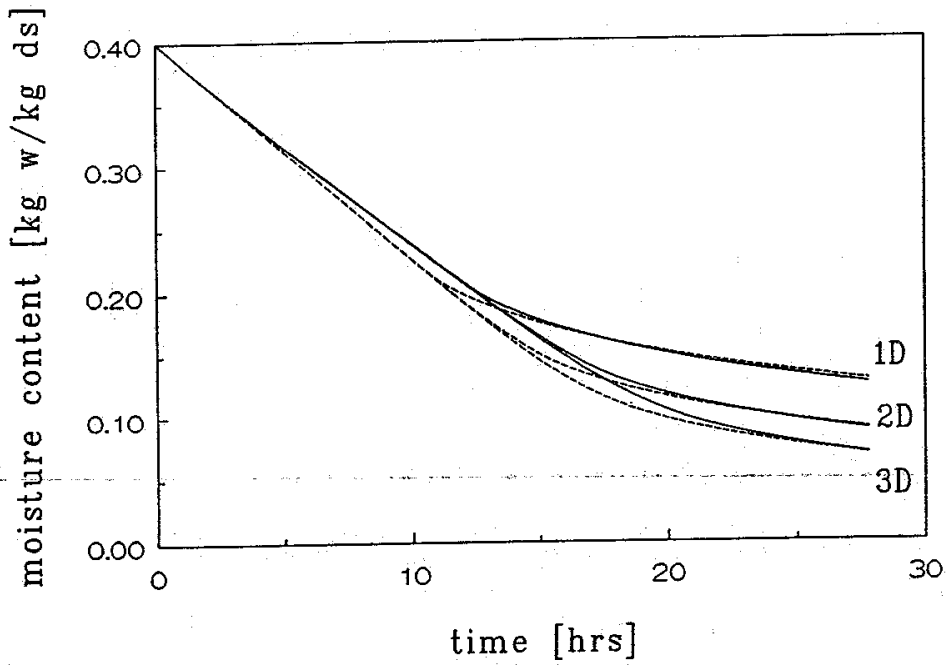

FIGURE 4. Drying curves for clay $A$ for multi-dimensional situations assuming isotropic $(-$ ) and no-shrinkage $(-\rightarrow$ ). One-dimensional (1D), two-dimensional (2D) and three-dimensional (3D) geometries respectively. 
The transition between the period of constant drying flux and the period of falling drying flux is smoother in the multi-dimensional situations than the onedimensional situation, for both the isotropic and no-shrinkage model. In the onedimensional situation the whole drying surface enters the period of falling drying flux at the same time, whereas in the multi-dimensional situations, parts of the surface closer to the corner will enter this period before parts more distant from the corner. Therefore the transition is smoother in the latter case.

From the results presented here it can be concluded that an important influence is the decrease in surface area and a corresponding decrease in the drying rate. However, in all simulations it was found that after some time the drying curve for the no-shrinkage model is in fairly good agreement with the one for the isotropic shrinkage model. For practical applications this means that as long as interest is focused on drying curves only the influence of (isotropic) shrinkage in drying of clays is of minor importance.

\section{CONCLUSIONS}

In order to solve the diffusion equation numerically a transformation of the spatial coordinates to solid coordinates is introduced. The need for the inclusion of stresses in the model is circumvented here by making assumptions with regard to the shrinkage behaviour. Three shrinkage models have been elaborated. Given the diffusion coefficient of a material, drying behaviour will depend on the shrinkage model. Simulations have been performed to quantify this effect.

From simulations of one-dimensional drying - of a-thin slab $(3 \mathrm{~mm})$, it was concluded that the major influence of isotropic shrinkage is the reduction of the surface area. For clays, however, this effect is relatively small since soon after the period of falling drying flux has started, the drying curves of the isotropic shrinkage model and of the no-shrinkage model merge. The drying curve calculated by the unidirectional shrinkage model deviates considerably from the isotropic shrinkage model over a long period of time. 
Multi-dimensional simulations with larger cubes $(5 \times 5 \times 5 \mathrm{~cm})$ confirm the difference between the no-shrinkage model and the isotropic shrinkage model. Generally the observed behaviour is in agreement with the behaviour of the thin slab. From the results it can be concluded that the influence of shrinkage is negligible if one is only interested in the necessary drying time to reach relatively low moisture contents.

Acknowledgements-This work was financially supported by the Nederlandse Maatschappij voor Energie en Milieu B.V. (NOVEM), the Koninklijk Verbond van Nederlandse Baksteenfabrikanten (KNB), the Nederlandse Dakpannenfabrikanten Corporatie (Nedaco) and performed in coorperation with the TNO-TPD department of ceramics.

\section{NOTATION}

$\begin{array}{lll}\mathbf{C} & = & \text { vapour concentration }\left[\mathrm{kg} \mathrm{m}^{-3}\right] \\ \mathbf{D} & =\text { diffusion coefficient }\left[\mathrm{m}^{2} \mathrm{~s}^{-1}\right] \\ \mathbf{k} & =\text { mass transfer coefficient }\left[\mathrm{m} \mathrm{s}^{-1}\right] \\ \underline{\mathrm{n}} & =\text { unit normal vector } \\ \underline{t} & =\text { time }[\mathrm{s}] \\ \underline{u} & =\text { solid based moisture content }\left[(\mathrm{kg} \text { moisture })(\mathrm{kg} \text { solid })^{-1}\right] \\ \underline{\mathrm{v}} & =\text { velocity }\left[\mathrm{m} \mathrm{s}^{-1}\right] \\ \underline{\mathbf{x}} & =\text { spatial coordinate }[\mathrm{m}] \\ \underline{\mathbf{z}} & =\text { solid coordinate }[\mathrm{m}]\end{array}$

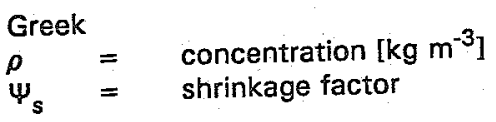

Super- and subscripts

$i=$ interface

$m=$ moisture

s $=$ solid

sat $=$ saturated

0 initial, at $\mathrm{t}=0$

$1,2,3=$ coordinate directions

$\infty=$ bulk of drying air

\section{REFERENCES}

Coumans, W.J., 'Power Law Diffusion in Drying Processes', Ph.D. thesis, Eindhoven University of Technology, 1987. 
Crank, J., 'The Mathematics of Diffusion', Oxford University Press, 1956.

Evans, A.A. and R.B. Keey, 'Moisture Diffusion Coefficient of a Shrinking Clay on Drying', Chem. Eng. J., 10, pp. 127-134, 1975.

Genskow, L.R., 'Considerations in Drying Consumer Products', in: Drying '89, A.S. Mujumdar \& M.A. Roques (eds), Hemisphere, pp. 38-46, 1989.

Jacobs, J., 'The Dutch Ceramic Industry', Klei/glas/keramiek, special ECerS edition, Pressofoon, Heemskerk, pp. 12-17, 1989.

Jomaa, W., W. Aregba, J.R. Puiggali and M. Quintard, 'Drying of Highly Shrinking Products: Application to Gels', Drying '91, A.S. Mujumdar \& I. Filkova (eds), pp. 110-121, Elsevier, Amsterdam, pp. 110-121, 1991.

Kaasschieter, E.F., 'A finite element method for modelling the drying of clays', Internal Note Department of Mathematics and Computing Science, Eindhoven University of Technology, the Netherlands, 1992 (in Dutch).

Kechaou, N. and M.A. Roques, 'A Variable Diffusivity Model for Drying of Highly Deformable Materials', in: Drying '89, A.S. Mujumdar \& M.A. Roques (eds), Hemisphere, pp. 332-339, 1989.

Ketelaars, A.A.J., 'Drying Deformable Media: Kinetics, Shrinkage and Stresses', Ph.D. thesis, Eindhoven University of Technology, 1992.

Lartigue, C., J.R. Puiggali and M. Quintard, 'A Simplified Study of Moisture Transport and Shrinkage in Wood', in: Drying '89, A.S. Mujumdar \& M.A. Roques (eds), Hemisphere, pp. 169-179, 1989.

Mujumdar, A.S., 'Drying Technologies of the Future', Drying Tech., $\underline{9}(2)$, pp. 325-348, 1991.

Philip, J.R., 'Hydrostatics and Hydrodynamics in Swelling Soils', Water Resour. Res., $5(5)$, pp. 1070-1077, 1969.

Roques, M.A., 'Heat and Mass Transfer in Polymer and Gel Drying', Drying '91, A.S. Mujumdar \& 1. Filkova (eds), Elsevier, Amsterdam, pp. 1-26, 1991.

Scherer, G.W., 'Drying gels II. Film and Flat Plate', J. Non-Cryst. Solids, 92, pp. 375-382, 1987.

Segal, G., 'Sepran Introduction Manual', Ingenieursbureau Sepra, Leidschendam, 1984

\section{APPENDIX}

The following material properties for a kaolinite clay were used in this study. For detailed information see [Ketelaars, 1992]: 
$-D(u)=1.10^{-9} e^{18 u}\left[\mathrm{~m}^{2} \mathrm{~s}^{-1}\right]$

- $C^{\infty}=0\left[\mathrm{~kg} \mathrm{~m}^{-3}\right]$

$-u_{0}=0.4\left[\mathrm{~kg} \mathrm{~kg}^{-1}\right]$

- initial drying flux $=k . C^{\text {sat }}=3.10^{-4}\left[\mathrm{~kg} \mathrm{~m}^{-2} \mathrm{~s}^{-1}\right]$

- desorption isotherm at $25^{\circ} \mathrm{C}: \mathrm{C} / \mathrm{C}^{\text {sat }}=\frac{1}{2}+\frac{1}{\pi}$ atan $\left(150 \mathrm{u}-\frac{2.10^{-4}}{1.10^{-99}+\mathrm{u}^{2}}\right)$

$-\Psi_{s}(u)=\frac{\rho_{s}}{\rho_{s, 0}}= \begin{cases}\frac{0.81}{0.41+u} & \text { for } u \geq 0.27 \\ \frac{0.81}{0.41+0.27} & \text { for } u \leq 0.27\end{cases}$

This equation can be derived from Figure 1. 